\title{
Chest pain during admission in a reference cardiac emergency unit
}

\author{
Dor torácica na admissão em uma emergência cardiológica de referência \\ Dolor torácico en la admisión en una urgencia cardiológica de referencia
}

\begin{abstract}
Eduardo Tavares Gomes ${ }^{1}$, Andrey Vieira de Queiroga ${ }^{1}$, Nyagra Ribeiro de Araujo ${ }^{1}$, Simone Maria Muniz da Silva
\end{abstract} Bezerra $^{1}$

This study aimed to verify the presence of chest pain in a reference emergency cardiac unit of Recife, PE, Brazil. This is a cross-sectional, descriptive-exploratory study, with a quantitative approach. Between December 2012 and February 2013, data from 39 patients admitted to the unit with chest pain were collected. For comparison between the averages, the MannWhitney test was used and the Pearson correlation was used to verify the association between numerical variables and pain scores and time between symptoms' onset and attendance (delta t). The main presentations were retrosternal chest pain isolated (51.3\%) and combined with radiation (33.3\%). The average scores reported for pain was $5.15 \pm 1.63$ and the delta $t$ of the sample was $14.95 \pm 8: 48 \mathrm{~h}$. The delay to arrive at the reference unit harms the diagnosis and the possibility of initiating reperfusion therapy in pre-hospital care should be considered.

Descriptors: Emergency Medical Services; Chest pain; Cardiology; Nursing.

Objetivou-se verificar a apresentação da dor torácica em uma unidade de referência em emergência cardiológica do Recife, PE, Brasil. Trata-se de um estudo de corte transversal, descritivo-exploratório, de abordagem quantitativa. Foram coletados entre dezembro de 2012 e fevereiro de 2013, dados de 39 pacientes admitidos na unidade com dor torácica. Para a comparação entre as médias foi utilizado o teste de Mann-Whitney e a correlação de Pearson foi utilizada para verificar a associação entre variáveis numéricas com os escores de dor e tempo entre início dos sintomas e atendimento (delta t). As principais apresentações foram a dor retroesternal isolada (51,3\%) e combinada à irradiações (33,3\%). 0 escore médio referido para dor foi de $5,15 \pm 1,63$ e o delta t da amostra foi de $14,95 \pm 8,48 \mathrm{~h}$. A demora até a unidade de referência prejudica o diagnóstico e deve-se considerar a hipótese de a terapia de reperfusão iniciar no atendimento pré-hospitalar.

Descritores: Serviços Médicos de Emergência; Dor no peito; Cardiologia; Enfermagem.

El objetivo fue verificar la presentación del dolor torácico en servicio de urgencia de referencia cardíaca de Recife, PE, Brasil. Estudio de corte transversal, descriptivo, exploratorio, cuantitativo. Fueron recogidos entre diciembre de 2012 y febrero de 2013 los datos de 39 pacientes ingresados en la unidad de dolor torácico. Para comparación entre las medias, fue utilizado test de Mann-Whitney y correlación de Pearson para verificar asociación entre variables numéricas con puntuaciones de dolor y tiempo entre el inicio de los síntomas y atendimiento (delta t). Las principales presentaciones fueron dolor retro esternal solo (51,3\%) y combinada con la irradiación (33,3\%). La puntuación promedia para dolor retro esternal solo fue de $5,15 \pm 1,63$ y el delta $\mathrm{T}$ de la muestra fue de 14,95 $\pm 8,48 \mathrm{~h}$. El retraso de la unidad de referencia perjudica el diagnóstico y debe considerarse la posibilidad de iniciar la terapia de reperfusión en la atención prehospitalaria.

Descriptores: Servicios Médicos de Urgencia; Dolor en el pecho; Cardiología; Enfermería.

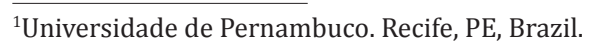




\section{Introduction}

Chest pain is the most common symptomatic expression of cardiac disorder in emergency services. The Coronary Artery Disease progresses to acute myocardial infarction with strong association to pain symptoms ${ }^{(1)}$. Multicenter studies listed as major risk factors dyslipidemia, hypertension, diabetes, smoking, obesity, physical inactivity and alcohol consumption ${ }^{(2-3)}$.

The association of chest pain to a cardiac event and its gravity has been identified as a factor that favored the early demand for an emergency service ${ }^{(4-6)}$. Considering the need of rapid intervention for chest pain, nurses must understand its presentation, investigate risk factors and investigate the possibility of non-cardiogenic origin and master protocols to better conduct patients from their arrival at the reference service, since it has already been verified the relationship between the delay in the conduction of an electrocardiogram and in the recognition of acute myocardial infarction as factors that hinder the administration of reperfusion therapy ${ }^{(7-9)}$.

In a recent study about the difficulties of hospital accreditation in a public cardiology institution, the nurses interviewed reported several relevant issues, in particular the need for established, updated protocols, for training and for ease of communication $^{(10)}$. These factors to be considered take unique proportion in an emergency cardiology unit, as a strategy for reducing in-hospital delay to reperfusion in myocardial infarction.

The chest pain units must know the network to which they are integrated in the regulatory process to facilitate the understanding of patients' presentation. Through this study, one aimed at verifying the presentation of chest pain in a reference unit of cardiac emergency in Recife-PE. Studies like this allow for services a better understanding of the phenomenon and planning of the assistance to be provided, besides bringing reflection about the possibilities of failure in reperfusion therapy within the therapeutic time.

\section{Method}

This is a cross-sectional, descriptiveexploratory study, with a quantitative approach, performed in a cardiac emergency service reference in the city of Recife-PE. Data were collected between December 2012 and February 2013, from 39 patients admitted to the emergency service, in the period of up to 24 hours after entering the service. During the collection period, 72 patients with chest pain were attended, out of whom 32 were excluded for being clinically unable or because they were taken to angiography, thrombolysis or intensive care unit.

The instrument of data collection was developed containing socio-demographic and clinical data (origin, years of education, age, sex, labor activity, per capita income, health history, blood pressure on admission, weight, height, body mass index), main complaint, time from onset of the symptoms, way of access to the service and information about the presentation of chest pain: location, radiation, duration. The labor activity was considered in terms of active to those with labor activity and inactive considering those who were unemployed or retired. Patients were classified as to their physical activity when they mentioned its practice, regardless of the frequency or nature of the activity, or sedentariness. Alcohol use was considered in number of times per week, regardless of the dose and smoking in number of cigarettes per day. The minimum wage in the period was R 622.00 (approximately US\$230).

The pain was recorded as typical retrosternal, retrosternal with radiation, which included any point between the mesogastric region and the jaw and atypical pain, which included non-classical presentations of anginal pain such as stabbing pain, epigastric pain, reports of heartburn/burning etc. For the pain score patients were asked to attribute a grade for their pain on an analog scale from 0 (zero) to 10 (ten) points, representing respectively the smallest and the greatest pain. The variation of time between onset of symptoms and arrival at the service 
is expressed by the term delta t. Data were collected through interviews with patients, consultation to their records of assessment and risk classification conducted by a nurse and to their health care records.

The Microsoft Excel 2012 software was used for the preparation of the database, and the analysis was performed using the statistical software Epi-info 7.0 and SPSS 20.0. The results are presented as absolute and relative frequencies, averages, medians, minimum and maximum values. For comparison between the averages the Mann-Whitney test and Pearson's correlation was used to assess the association between numerical variables with pain scores.

This study was based on the resolution of the Conselho Nacional de Saúde [National Health Council] in the period of the study - number 196/96 and had the consideration and approval of the research ethics committee of the Instituto de Medicina Integral de Pernambuco [Institute of Integral Medicine of Pernambuco] under protocol number 03198212.1.0000.5201.

\section{Results}

The sample showed a slight male predominance (51.3\%), aged over 60 years old $(56.41 \%, 60.33 \pm 11.73$ years). Regarding the socio-demographic variables, there were incomes up to three minimum wages (51.3\%), without labor activity (64.1\%), from the capital and metropolitan region of Recife (84.6\%), educational level until 15 years (64.1\%) (Table 1).

The chest pain had retrosternal presentation isolated in $51.3 \%$ of the cases and radiation combined in more 33.3\%. The atypical chest pain, encompassing stabbing pain, right hemithorax, with improvement after the use of painkillers, among others, occurred in only $15.4 \%$ of the patients who were diagnosed with non-cardiogenic pain (Table 1).

The majority of the patients were coming from other health units (64.1\%), being the first service in $35.9 \%$ of the cases. The transportation of these patients occurred in $79.49 \%$ by ambulances and other services, with only six cases $(15.38 \%)$ done by the Mobile Emergency Care Service (table 1).

Table 1 - Distribution of patients attended with chest pain in a reference cardiac emergency unit by sociodemographic and clinical characteristics

\begin{tabular}{|c|c|}
\hline Variables & n (\%) \\
\hline \multicolumn{2}{|l|}{ Sex } \\
\hline Male & $20(51.3)$ \\
\hline Female & $19(48.7)$ \\
\hline \multicolumn{2}{|l|}{ Age (in years) } \\
\hline $0-60$ & $22(56.4)$ \\
\hline$>60$ & $17(43.6)$ \\
\hline \multicolumn{2}{|l|}{ Labor activity } \\
\hline Inactive & $25(64.1)$ \\
\hline Active & $14(35.9)$ \\
\hline \multicolumn{2}{|l|}{ Provenance } \\
\hline Countryside & $6(15.4)$ \\
\hline Capital & $17(43.6)$ \\
\hline Recife's metropolitan region & $16(41.0)$ \\
\hline \multicolumn{2}{|l|}{ Income (minimum wage*) } \\
\hline $0-3$ & $20(51.3)$ \\
\hline$>3$ & $19(48.7)$ \\
\hline \multicolumn{2}{|l|}{ Years of study } \\
\hline $0-4$ & $10(25.6)$ \\
\hline $5-10$ & $5(12.8)$ \\
\hline $10-15$ & $10(25.6)$ \\
\hline$>15$ & $14(35.9)$ \\
\hline \multicolumn{2}{|l|}{ Location of pain } \\
\hline Retrosternal & $20(51.3)$ \\
\hline Retrosternal with radiation & $13(33.3)$ \\
\hline Atypical & $6(15.4)$ \\
\hline \multicolumn{2}{|l|}{ Origin } \\
\hline Home & $7(17.9)$ \\
\hline Street & 7 (17.9) \\
\hline Another health unit & $25(64.1)$ \\
\hline \multicolumn{2}{|l|}{ Form of access to the service } \\
\hline Own transportation & $2(5.1)$ \\
\hline Other ambulance services & $31(79.5)$ \\
\hline Mobile Emergency Care Service & $6(15.4)$ \\
\hline
\end{tabular}

Concerning their personal health history, overweight and obesity were found in $35.9 \%$ of the patients, being the average of body mass index $24.6 \pm 2.6 \mathrm{~kg} / \mathrm{m}^{2}$, diabetes in use of oral hypoglycemic drugs (33.3\%) and insulin (20.5\%), hypertension 
drug treatment in $79.5 \%$ of the cases, low frequency or denial of alcohol consumption in $76.9 \%$, smoking in $46.1 \%$. Out of the patients $28.2 \%$ had history of cerebrovascular accident and $35.9 \%$ had a previous diagnosis of any heart diseases before the onset of chest pain (table 2).

Table 2 - Personal health history of patients with chest pain in a cardiac emergency unit

\begin{tabular}{|c|c|}
\hline Variables & n (\%) \\
\hline \multicolumn{2}{|l|}{ Weight } \\
\hline Normal & $25(64.1)$ \\
\hline Overweight and obesity & $14(35.9)$ \\
\hline \multicolumn{2}{|l|}{ Diabetes } \\
\hline Denies / Does not know & $18(46.1)$ \\
\hline Using oral hypoglycemic drugs & $13(33.3)$ \\
\hline Using insulin & $8(20.5)$ \\
\hline \multicolumn{2}{|l|}{ Hypertension } \\
\hline Denies / Does not know & $8(20.5)$ \\
\hline Drug treatment $<2$ years & $4(10.3)$ \\
\hline Drug treatment between $2-5$ years & $10(25.6)$ \\
\hline Drug treatment between 6 - 10 years & $8(20.5)$ \\
\hline Drug treatment $>10$ years & $9(23.1)$ \\
\hline \multicolumn{2}{|l|}{ Alcohol consumption (times per week) } \\
\hline Denies consumption & $13(33.3)$ \\
\hline 1 & $17(43.6)$ \\
\hline $2-3$ & $5(12.8)$ \\
\hline+3 & $4(10.3)$ \\
\hline \multicolumn{2}{|l|}{ Smoking (cigarettes/day) } \\
\hline Denies use & $21(53.8)$ \\
\hline Up to 10 cigarettes a day & $15(38.5)$ \\
\hline$>10$ cigarettes per day & $3(7.7)$ \\
\hline \multicolumn{2}{|l|}{ Previous heart disease } \\
\hline Yes & $14(35.9)$ \\
\hline No & $25(64.1)$ \\
\hline \multicolumn{2}{|l|}{ Stroke } \\
\hline Yes & $11(28.2)$ \\
\hline No & $28(71.8)$ \\
\hline
\end{tabular}

The average chest pain of the sample was of $5.1 \pm 1.6$ points, with higher scores among men $(6.0 \pm 1.6$, median 6) compared to women ( $4.3 \pm 0.9$, median 4) $(p<0.001)$. (Table 3) Although there is no significant difference between the pain scores in the age group over 60 years old $(p=0.16)$, there was a moderate association between decreased age and increased values of referred pain $(p=0.012)$, corroborating with higher averages among youngsters (Table 4). There was no significant difference among the pain averages concerning the work activity ( $\mathrm{p}=0.42)$, hypertension $(\mathrm{p}=0.38)$, alcohol use $(\mathrm{p}=0.83)$, smoking $(\mathrm{p}=0.26)$, sedentariness $(p=0.11)$, previous diagnosis of heart disease $(\mathrm{p}=0.16)$ or previous stroke $(\mathrm{p}=0.33)$. (Table 3) Non-diabetic patients had higher average of selfreported pain (6.3 \pm 1.5 , median 6.0 ) compared to diabetic patients $(4.2 \pm 1.0$, median 4.0$)(\mathrm{p}<0.001)$ (Table 3).

Table 3 - Assessment of the value of reported chest pain according to socio-demographic and clinical characteristics of the sample

\begin{tabular}{|c|c|c|c|c|}
\hline Variables & $\begin{array}{c}\text { Average } \\
\pm \text { SD }\end{array}$ & Median & $\begin{array}{l}\text { Mín- } \\
\text { Máx }\end{array}$ & $\mathbf{p}^{*}$ \\
\hline Sample & $5.1 \pm 1.6$ & 5 & $3.0-9.0$ & \multirow{3}{*}{$<0.001$} \\
\hline Men & $6.0 \pm 1.7$ & 6 & $3.0-9.0$ & \\
\hline Women & $4.3 \pm 0.9$ & 4 & $3.0-6.0$ & \\
\hline Up to 60 years old & $5.5 \pm 1.9$ & 6 & $3.0-9.0$ & \multirow{2}{*}{0.16} \\
\hline$>60$ years old & $4.6 \pm 0.9$ & 5 & $3.0-6.0$ & \\
\hline Active & $5.3 \pm 1.7$ & 5 & $3.0-9.0$ & \multirow{2}{*}{0.42} \\
\hline Inactive & $4.9 \pm 1.6$ & 4 & $3.0-8.0$ & \\
\hline Diabetic & $4.2 \pm 1.0$ & 4 & $3.0-6.0$ & \multirow{2}{*}{$<0.001$} \\
\hline Nondiabetic & $6.3 \pm 1.5$ & 6 & $4.0-9.0$ & \\
\hline Hypertensive & $5.9 \pm 2.4$ & 6 & $3.0-9.0$ & \multirow{2}{*}{0.38} \\
\hline Nonhypertensive & $4.9 \pm 1.3$ & 5 & $3.0-8.0$ & \\
\hline Alcohol use & $5.2 \pm 1.6$ & 5 & $3.0-8.0$ & \multirow{2}{*}{0.83} \\
\hline Do not use alcohol & $5.1 \pm 1.7$ & 5 & $3.0-9.0$ & \\
\hline Cigarette use & $5.4 \pm 1.7$ & 5 & $3.0-9.0$ & \multirow{2}{*}{0.26} \\
\hline No cigarette use & $4.8 \pm 1.6$ & 4 & $3.0-8.0$ & \\
\hline Sedentary & $5.9 \pm 2.0$ & 5 & $3.0-9.0$ & \multirow{2}{*}{0.11} \\
\hline Non-sedentary & $4.8 \pm 1.2$ & 5 & $3.0-7.0$ & \\
\hline Cardiac disease & $5.6 \pm 1.5$ & 5 & $3.0-8.0$ & \multirow{2}{*}{0.16} \\
\hline No cardiac disease & $4.9 \pm 1.6$ & 5 & $3.0-9.0$ & \\
\hline Previous stroke & $5.5 \pm 1.6$ & 5 & $3.0-8.0$ & \multirow{2}{*}{0.33} \\
\hline No previous stroke & $5.0 \pm 1.6$ & 5 & $3.0-9.0$ & \\
\hline Delta $\mathrm{t}<12 \mathrm{~h}$ & $5.9 \pm 1.8$ & 6 & $3.0-9.0$ & \multirow{2}{*}{0.02} \\
\hline Delta $t \geq 12 \mathrm{~h}$ & $4.5 \pm 1.1$ & 5 & $3.0-6.0$ & \\
\hline
\end{tabular}

There was a higher pain average among patients with up to 12 hours after the onset of symptoms (5.9 \pm 1.8 , median 6.0$)$ in relation to those who waited for more than 12 hours $(4.5 \pm 1.14 \mathrm{~h}$ median 5.0$)$ $(\mathrm{p}=0.02)$, verifying a moderate association between the time from the onset of symptoms until the arrival at the emergency unit (delta $t$ ) and pain score $(r=0.34$, 
$\mathrm{p}=0.035$ ). (Tables 3 and 4 ) The delta t of the sample was of $14.9 \pm 8.5 \mathrm{~h}$. Blood pressure levels on admission were: systolic blood pressure of $145.1 \pm 17,1 \mathrm{mmHg}$ and diastolic of $88.4 \pm 13,5 \mathrm{mmHg}$, both with weak association $(\mathrm{r}=0.24)$ and moderate $(\mathrm{r}=0.30)$ with the pain score, but without statistical significance ( $p=0.135$ and 0.065 , respectively) (Table 4).

Table 4 - Correlation between the value referred for chest pain in patients attended in a cardiac emergency unit with age, blood pressure, body mass index and interval between the onset of symptoms and attendance

\begin{tabular}{lccc}
\hline Variables & Average \pm SD & $\boldsymbol{r}^{*}$ & $\mathbf{p}$ \\
\hline Age & $60.3 \pm 11.7$ & -0.4 & 0,012 \\
Systolic blood pressure & $145.1 \pm 17.1$ & 0.24 & 0,135 \\
Diastolic blood pressure & $88.4 \pm 13.5$ & 0.30 & 0,065 \\
Body mass index & $24.6 \pm 2.6$ & 0.11 & 0.49 \\
Delta t & $14.9 \pm 8.5$ & 0.34 & 0,035 \\
\hline * Pearson's correlation coefficient & & &
\end{tabular}

\section{Discussion}

Diseases of the heart and of the circulatory system are still the leading cause of deaths in Brazil, accounting for nearly $32 \%$ of all deaths ${ }^{(11)}$. Acute myocardial infarction is still a major cause of morbidity and mortality. The breakthrough that occurred in the treatment of myocardial infarction through reperfusion with fibrinolytic therapy or through primary angioplasty was not enough to prevent it from continuing with high morbidity and mortality.

The sociodemographic profile of the sample was similar to other studies, revealing mainly an average age above 60 years old, a slight predominance of males and the presence of cardiovascular risk factors classically reported in the literature ${ }^{(4,12-14)}$. Lower income favors diseases and complicates the recognition of the signs and symptoms of acute myocardial infarction ${ }^{(12)}$.

The significant association between the score assigned to the chest pain and delta $t$ found corroborates other studies that also found the fastest search for service of patients with higher pain intensity ${ }^{(6)}$. A previous study also showed lower averages of pain for diabetic patients compared with non-diabetic ones, and in other international researchers found bigger complications related to the diabetic group ${ }^{(1,15)}$. Overweight and obesity were present in frequencies above the Brazilian population, and even not having significant association with pain values, they are important modifiable risk factors for the event $t^{(4,11,13)}$. The presence of overweight and obesity in national studies with patients who have acute coronary syndrome in emergency attendance has been found until a frequency of $77 \%{ }^{(4)}$.

The percentage of atypical presentations for chest pain found in the sample may hinder the search for emergency services. The symptoms of heart attack can be mistaken for gastrointestinal, muscular and respiratory symptoms, increasing the delay for attendance $\mathrm{e}^{(9,16)}$. Chest pain associated with other symptoms such as syncope and dyspnea, are more likely to motivate the search for specialized care ${ }^{(17)}$.

A national study found that $53 \%$ sought the service within 12 hours, with worse outcomes for patients who exceeded this time and that only $36.5 \%$ of the sample acknowledged that the symptoms were cardiovascular, mistaking them up with food or drug poisoning $(8.5 \%)^{(12)}$. Female gender, more comorbidities, longer duration of symptoms, transport by means other than an ambulance were reported in an international study as pre-hospital risk factors for the delay in the administration of thrombolytic therapy ${ }^{(7)}$. A recent Iranian study found that a delay in the administration of thrombolytic therapy was related to retardation in recognizing the event as a cardiac problem or to recognize the gravity of the symptoms, increasing in up to 2 hours the delta $t^{(7)}$. Another study sample revealed that the reasons to seek specialized services were in $66 \%$ of the cases, no longer putting up with the pain, and $33 \%$ who might die; while the non-recognition of the gravity was the 
main factor that favored the procrastination ${ }^{(5)}$.

The need for early reperfusion is crucial for good prognosis of myocardial infarction. The average delta $t(14.9 \pm 8.5)$ over 12 hours, and the association with worsening of the pain, worsens the prognosis of patients by taking away from patients the possibility of reperfusion. Considering that most of the patients came from other services (64.1\%), one should reflect on the use of fibrinolytic agents in fixed and mobile pre-hospital environment. Transport by ambulance (94.9\%) was not enough to reduce high delta $t$, considered as a factor that facilitates access to the service, probably due to the time spent in the attendance on the first unit ${ }^{(18)}$. A recent Brazilian study in a reference center also presented high delta $t$ in the general sample ( $9 \mathrm{~h} 5 \mathrm{~min} \pm 18 \mathrm{~h} 9 \mathrm{~min})$, considering averages of other countries and lower values when the transportation was done by ambulances $(7 \mathrm{~h} 4 \mathrm{~min} \pm 11 \mathrm{~h} 3 \mathrm{~min})^{(17-19)}$.

It is known that the distance between the residence and the reference attendance unit worsens the prognosis in several cities and the reperfusion therapies end up centralized in references units ${ }^{(20)}$. Studies verifying the alternative of reperfusion in the pre-hospital environment in the Brazilian health system showed that it improves survival and reduces the cost compared to in-hospital thrombolysis ${ }^{(21)}$. The development of protocols for hospital emergency units is also crucial in order to reduce waiting time and to favor thrombolysis, considering the limited therapeutic pre-hospital approach ${ }^{(8)}$.

\section{Conclusion}

Chest pain has its own characteristic presentation, widespread among health professionals. Then, nurses, who are directly involved with the attention to acute myocardial infarction, should know this clinical condition very well and how to interpret it and to differentiate cardiogenic pain.
In primary prevention, health education can minimize its effects indirectly, by addressing risk factors, control of hypertension and diabetes, or directly, clarifying the population about the early signs and symptoms of acute myocardial infarction. Knowledge about chest pain and what it represents should be widespread for patients to acknowledge it and seek early attendance, avoiding the delay due to self-medication or for not making association with the severity and cause of the cardiogenic episode.

Within the secondary prevention, it is of paramount importance for nurses the knowledge about chest pain, considering that it is responsible for the welcoming and risk classification in emergency services. This understanding gives nurses the option to prioritize chest pain and start the attendance as soon as possible. From the perspective of the reference system of the current organization of health care networks in the cities, there is sufficient evidence of the need for thrombolysis in pre-hospital care. Moreover, in coronary care units, protocols for attendance of chest pain should be well designed and be known by everyone involved, reducing the inhospital delay to the reperfusion therapy.

This study was limited by the small sample size, as it reflects the early months of attendance to urgency and emergency cardiac cases in the health unit. However, it proved to be of great value in the initial moment of planning and adjustments through which the service has gone, to improve the attendance to chest pain and implement an institutional assistance protocol.

\section{Collaborations}

Gomes ET, Queiroga AV, Araujo NR and Bezerra SMMS contributed to the design, analysis, interpretation of data, drafting of the article and final approval of the version to be published. Gomes ET contributed to the data collection, statistical analysis, data interpretation and writing of the article. 


\section{References}

1. Paim CP, Azzolin KO, Moraes MAP. Dor torácica no infarto agudo do miocárdio entre pacientes diabéticos e não diabéticos. Rev Bras Enferm. 2012; 65(1):77-82.

2. McGorain C, Yusuf S, Islam S, Jung H, Rangarajan $\mathrm{S}$, Avezum A et al. Estimating modifiable coronary heart disease risk in multiple regions of the world: the Interheart Modifiable Risk Score. Eur Heart J. 2011; 32:581-90.

3. Lemos KF, Davis R, Moraes MA, Azzolin K. Prevalence of risk factors for acute Coronary Syndrome in patients treated in an emergency. Rev Gaúcha Enferm. 2010; 31(1):129-35.

4. Lemos DM, Teixeira CSS, Polanczyk CA, Rabelo ER. Trigger points for pain in patients with acute coronary syndrome. Rev Enferm UFSM. 2012; 2(3):480-6.

5. Damasceno CA, Queiroz TL, Santos CAST, Mussi FC. Factors associated with the decision to seek health care in myocardial infarction: gender differences. Rev Esc Enferm USP. 2012; 46(6):1362-70.

6. Lam Lambert JL, Brown KA, Boothroyd LJ, Segal E, Maire S, Kouz S, et al. Transfer of patients with st-elevation myocardial infarction for primary percutaneous coronary intervention: a provincewide evaluation of "Door-in to Door-Out" Delays at the First Hospital. Circulation. 2014; 129:265360.

7. Momeni M, Salari A, Shafighnia S, Ghanbari A, Mirbolouk F. Factors influencing pre-hospital delay among patients with acute myocardial infarction in Iran. Chin Med J. 2012; 125(19):3404-9.

8. Escosteguy CC, Teixeira AB, Portela MC, Guimarães AE, Lima SM, Ferreira VM et al. Implementing clinical guidelines on acute myocardial infarction care in an emergency service. Arq Bras Cardiol. 2011; 96(1):18-25.

9. Domingues GRS, Moraes-Filho JPP. Non-cardiac chest pain. Arq Gastroenterol. 2009; 46(3):23340.
10. Korayashi RM, Vendramini e Silva AB, Ayoub AC. Gerenciando dificuldades para a acreditação hospitalar em hospital cardiovascular. Rev Rene. 2010; 11(4):19-28.

11. Sociedade Brasileira de Cardiologia, Sociedade Brasileira de Hipertensão, Sociedade Brasileira de Nefrologia. VI Diretrizes Brasileiras de Hipertensão. Arq Bras Cardiol. 2010; 95(supl.1):151.

12. Gouveia VA, Victor EG, Lima SG. Pre-hospital attitudes adopted by patients faced with the symptoms of acute myocardial infarction. Rev Latino-am Enfermagem. 2011; 19(5):1080-7.

13. Barbosa, MH, Tavares JL, Andrade EV, Silva QCG, Diniz MA, Resende LAPR, Cardoso GL. Aspectos clínicos e epidemiológicos dos clientes submetidos à cineangiocoronariografia. Rev Min Enferm. 2011; 15(1):42-6.

14. Santos ES, Timerman A, Baltar VT, Castilho MTC, Pereira MP, Minuzzo L, et al. Dante Pazzanese risk score for non-st-segment elevation acute coronary syndrome. Arq Bras Cardiol. 2009; 93(4):343-51.

15. Dimitrov NG, Simova II, Mateev HF, Kalpachka MR, Pavlov PS, Tasheva IG. Timing of invasive strategy in diabetic and non-diabetic patients with nonST-segment elevation acute coronary syndrome. Folia Med. 2013; 55(2):16-25.

16. Wertli MM, Ruchti KB, Steurer J, Held U. Diagnostic indicators of non-cardiovascular chest pain: a systematic review and meta-analysis. BMC Med. 2013; 11(1):239.

17. Bastos AS, Beccaria LM, Contrin LM, Cesarino CB. Time of arrival of patients with acute myocardial infarction to the emergency department. Rev Bras Cir Cardiovasc. 2012; 27(3):411-8.

18. Karabulut A, Cakmak M, Uzunlar B, Topçu K. Impact of emergency services and ambulance type on pain-to-balloon time in the acute myocardial infarction: an observational study. Anadolu Kardiyol Derg. 2012; 12(1):23-9.

19. Khrain F, Carey M. Predictors of pre-hospital delay among patients with acute myocardial infarction. Patient Educ Couns. 2009; 75(2):155-61. 
20. Shen YC, Hsia RY. Does Decreased Access to Emergency Departments Affect Patient Outcomes? Analysis of AMI population 1996-2005. Health Serv Res. 2012; 47(1):188-210.

21. Araujo DV, Tura BR, Brasileiro AL, Neto HL, Pavão ALB. Cost-effectiveness of prehospital versus inhospital thrombolysis in acute myocardial infarction. Arq Bras Cardiol. 2008; 90(2):100-7. 